\title{
PRESENÇA DO TEMA SUSTENTABILIDADE NOS CURRÍCULOS E PROJETOS POLÍTICOS PEDAGÓGICOS DOS CURSOS DE ARQUITETURA E ENGENHARIA CIVIL
}

Raphaela Kimie Hisamatsu Smaniotto - raphaelahisamatsu@ufpr.br UFPR, Programa de Pós-Graduação em Engenharia de Construção Civil Centro Politécnico. Av. Cel. Francisco H. dos Santos, s/n.

81.312-050 - Curitiba - Paraná

Sérgio Fernando Tavares - sergio.tavares@ufpr.br

UFPR, Programa de Pós-Graduação em Engenharia de Construção Civil Centro Politécnico. Av. Cel. Francisco H. dos Santos, s/n.

81.312-050 - Curitiba - Paraná

Maria do Carmo Duarte Freitas - mcf@ufpr.br

UFPR, Programa de Pós-Graduação em Gestão da Informação

Campus Botânico. Av. Prefeito Lothário Meissner, 632

80210-170 - Curitiba - Paraná

Resumo: Apesar de se passarem cerca de 50 anos do "despertar ecológico" mundial, e de existir no Brasil número expressivo de grupos de pesquisa sobre sustentabilidade nos programas de pós-graduação bem como pesquisa consolidada sobre o tema, a Sustentabilidade ainda não é uma realidade no exercício profissional e no ambiente construído brasileiros. Isso vai ao encontro do problema de pesquisa: como tornar acessivel e compreensível aos profissionais da construção civil a produção acadêmica voltada à sustentabilidade ambiental, de modo a equalizar e democratizar esse conhecimento produzido nos cursos de pós-graduação e estimular a sua aplicação no exercício profissional? A natureza desta pesquisa é documental, exploratória e aplicada, e tem como objetivo mapear a presença do tema sustentabilidade (dentro de sua dimensão ambiental) nos currículos dos cursos de arquitetura e urbanismo e engenharia civil das instituições de ensino (IES) públicas brasileiras. Essas informações serão úteis para a pesquisa maior na medida que fornecem dados sobre que instituições e cursos carecem de disciplinas sobre sustentabilidade, bem como auxiliarão no estabelecimento de uma rede de contatos que na próxima etapa da pesquisa venham a validar o artefato a ser desenvolvido - MOOC ${ }^{1}$ sobre Telhados Verdes, modelo de curso que tem como objetivo compartilhar com graduandos e profissionais da construção civil a produção acadêmica do programa de pós-graduação sobre esta técnica de construção mais sustentável.

Palavras-chave: Sustentabilidade, Ensino Superior, Construção Civil, Arquitetura, Engenharia Civil.

\footnotetext{
${ }^{1}$ MOOC: Anagrama para Massive Open Online Course, que em português traduz-se por curso massivo, online e aberto.
} 


\section{INTRODUÇÃ̃O}

As interferências sobre o ambiente natural atingiram uma escala preocupante a partir da Revolução Industrial, quando ocorreu a transição da sociedade agrícola para a sociedade urbana e industrializada (KELLER; VIADYA, 2018), com a instalação de um modelo econômico linear, o qual busca o desenvolvimento econômico e tecnológico sem considerar a condição finita dos recursos naturais. O setor da Construção Civil configura-se como importante ator dentro deste cenário, pois além de ser um dos setores que mais consomem recursos naturais, $50 \%$ de toda a energia gerada no mundo é consumida pelas edificações (HEYWOOD, 2015). Por outro lado, há um grande potencial de aplicabilidade de estratégias e novas tecnologias para mitigação desses impactos.

O agravamento dos problemas ambientais nas últimas décadas - mudanças climáticas, crise energética, poluição da terra, água e ar, ameaça a flora e fauna, levaram a questionamentos em relação a estes modelos econômicos e padrões de consumo. Isso levou a iniciativas que visavam a sustentabilidade, por investimentos e incentivos fiscais para a incorporação de estratégias e tecnologias de menor impacto ambiental (OBERNDORFER, 2007).

A realidade brasileira não acompanhou a tendência europeia, em primeiro lugar devido à inércia do setor da construção civil, que diferentemente de outros setores da indústria, ainda se mantém preso à tradição construtiva em alvenaria e concreto, materiais que representam grande impacto ambiental em todas as fases do ciclo de vida. Em segundo lugar, e o pressuposto desta pesquisa, de que os cursos de graduação de engenharia civil e arquitetura e urbanismo do Brasil não estão desenvolvendo em seus egressos as competências necessárias para a formação de profissionais capacitados em soluções e tecnologias construtivas que visam a sustentabilidade ambiental.

\section{SUSTENTABILIDADE COMO TEMÁTICA NO CONTEXTO BRASILEIRO}

Segundo a resolução do MEC (BRASIL, 2012), foram estabelecidas as diretrizes curriculares nacionais para a Educação Ambiental, que tem por objetivo principal estimular a inserção da temática no processo ensino-aprendizagem por meio da reestruturação dos projetos pedagógicos. A resolução não exige que o tema seja abordado na matriz curricular, mas que esteja presente de forma transversal como elemento norteador das abordagens educacionais. Entretanto, do ponto de vista do ensino na construção civil, essas inserções mostraram pouca influência, pois ainda hoje a sustentabilidade ambiental não se apresenta como realidade consolidada no exercício profissional do setor (XAVIER, 2011).

Para que novas técnicas que visam a sustentabilidade ambiental sejam realidade no ambiente da construção civil, pressupõe-se a necessidade de se investir na capacitação dos profissionais envolvidos. Além de viabilizar o desenvolvimento social, tecnológico e econômico, é importante considerar o papel da educação como caminho para alterar a cultura construtiva no exercício dos profissionais da construção civil.

“A Universidade é um microcosmo da comunidade maior” (CORTESE, 2003, 19 pp.) A frase nos leva a refletir sobre o papel das Instituições de Ensino Superior (IES) como elemento que influencia e é influenciado pelo espaço que atua, atuando como agente de mudança e transformação. Devem ser o exemplo e vivenciar na prática os conceitos que preconizam, incutindo em seus egressos a sensibilidade e responsabilidade em se construir espaços saudáveis e ambientalmente sustentáveis. 
Entretanto, não é o que se vê. Como dito por Pergher e Freitas (2019) a presença da sustentabilidade ainda não é percebida na prática, ficando restrito a discursos e intenções. Essa situação pode estar relacionada à dificuldade das instituições, sobretudo as tradicionais, em vencer a inércia e realizar mudanças curriculares significativas. O resultado disso é um currículo ultrapassado, com foco excessivo no conteúdo tradicional, que não prepara o egresso para a real demanda do mercado de trabalho; nem mesmo propicia a inovação. Não seja por estagiar em empresas atuantes na indústria da construção civil e realizar cursos de capacitação, o egresso terá dificuldades para se encaixar no mercado de trabalho, quiçá conquistará oportunidades no contexto exterior. Para melhorar seu currículo, tanto graduandos como egressos se veem na situação de buscar em especializações a bagagem que não recebem/receberam na graduação.

Por isso a importância em se repensar os currículos e projetos políticos pedagógicos de maneira sistêmica e interdisciplinar, baseado na cooperação e colaboração entre os docentes. Baseando-se no perfil desejado do egresso, ou quais competências pretende-se desenvolver no estudante para que ele corresponda às expectativas e demandas do mercado de trabalho e da sociedade.

\section{SUSTENTABILIDADE NOS CURRÍCULOS DAS IES PÚBLICAS BRASILEIRAS}

De modo a mapear a presença do tema Sustentabilidade nos cursos de graduação da área de Construção Civil - Engenharia Civil e Arquitetura, utilizou-se como procedimento metodológico a leitura das matrizes curriculares desses cursos na busca por disciplinas que abordassem a temática, seja em seu título como em sua ementa. Foi realizado inicialmente um levantamento junto ao Portal do MEC, sendo encontrados 841 cursos de Arquitetura e Urbanismo, e 1420 cursos de Engenharia Civil, públicos e privados (BRASIL, 2020).

No entendimento da complexidade desta pesquisa e de modo a dar tangibilidade ao tratamento de dados, foi definido um recorte metodológico que determinou como unidade de análise as IES públicas das esferas municipal, estadual e federal, visto que como foi verificado por Pergher e Freitas (2019) 84\% dos grupos de pesquisa atuantes na área de sustentabilidade encontram-se nas instituições públicas. O recorte levou a um total de 203 instituições, sendo que dessas apenas 114 possuem cursos de Engenharia Civil ou Arquitetura, 27\% delas apresentando ambos os cursos. Esses dados estão expressos no Gráfico 1. 
(C) COBENCE

"Os desafios para formar hoje o engenheiro do amanhã"
29 de setembro a

O2 de outubro

Bento Gonçalves/RS

Gráfico 1 - Cursos de Engenharia Civil - Arquitetura e Urbanismo nas IES públicas brasileiras.

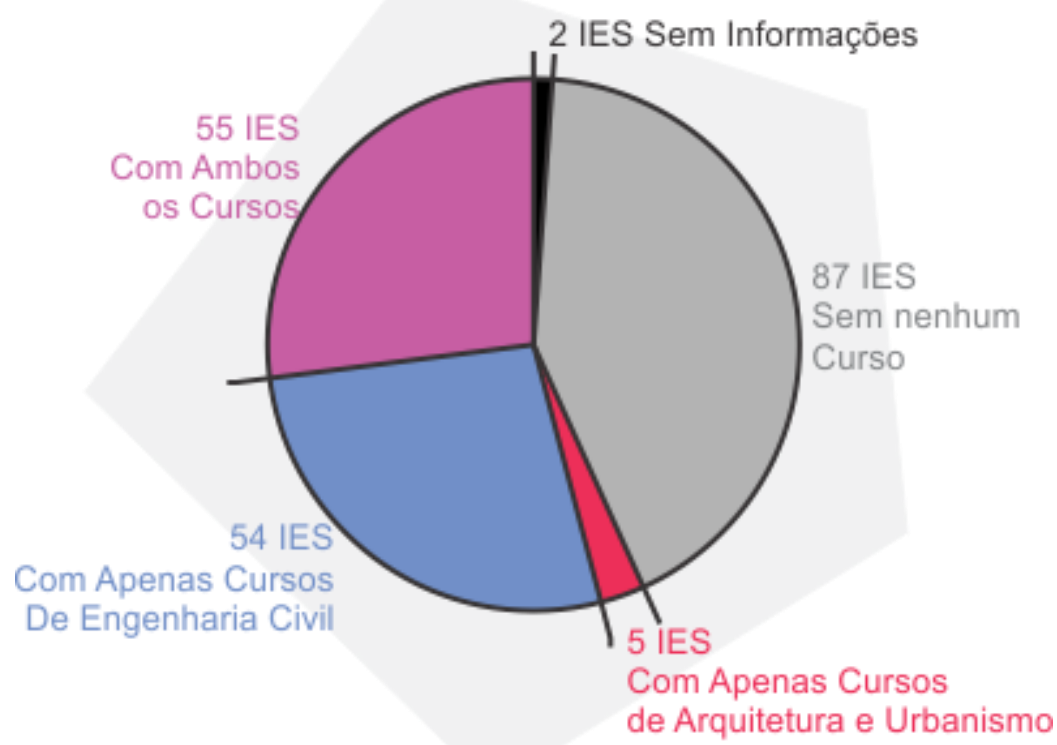

Fonte: Os Autores, 2020.

Na etapa seguinte foi realizada pesquisa junto às páginas web das instituições, pró-reitorias e departamentos dos cursos de engenharia e arquitetura, em busca da grade / matriz curricular e do Projeto Político Pedagógico (PPP) vigentes (Gráfico 2). Dentre os 169 cursos encontrados, 41 deles não dispunham de matriz curricular e/ou projeto político pedagógico nos sites. Estabeleceu-se então contato com as coordenações, colegiados e departamentos dos cursos por correio eletrônico. Entretanto, dentre os 41 cursos com materiais faltantes, dois deram retorno e apenas um dispunha do material solicitado.

Gráfico 2 - Levantamento dos currículos e PPP dos cursos.

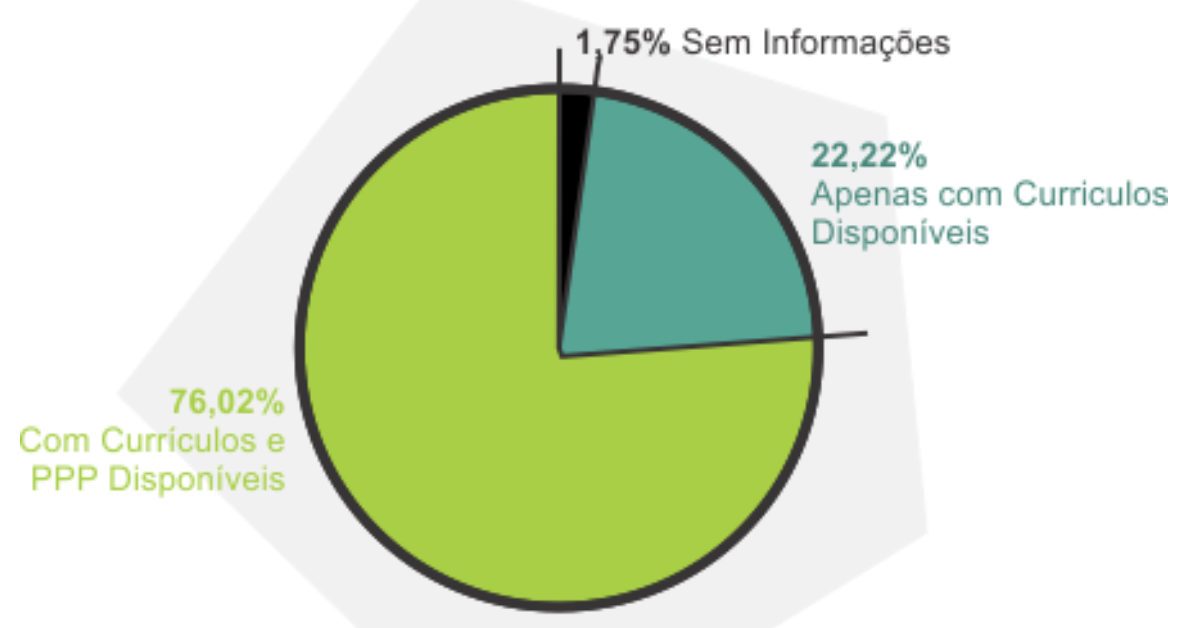

Fonte: Os autores, 2020 
(C) COBENCE

"Os desafios para formar hoje o engenheiro do amanhã"
29 de setembro a

$\mathrm{O} 2$ de outubro

Bento Gonçalves/RS

Após a reunião do material, deu-se início à análise curricular, e o critério adotado foi a presença/ausência do termo "Sustentabilidade" nos títulos das disciplinas. Após a leitura da matriz curricular, caso o termo "Sustentabilidade" não estivesse presente, foi realizada uma segunda leitura com o intuito de identificar títulos correlatos (Quadro 1), como, por exemplo "Gestão Ambiental" e "Conforto Ambiental".

Quadro 1 - Exemplos de Títulos correlatos cujo termo "Sustentabilidade" constou na ementa

\begin{tabular}{|c|c|c|}
\hline Conforto Ambiental & Gestão Ambiental & Gestão do Meio Ambiente \\
\hline Ciências do Ambiente & Eficiência Energética & $\begin{array}{c}\text { Conservação e Uso Eficiente } \\
\text { da Energia }\end{array}$ \\
\hline Ecodesign & Energias Renováveis & Estudos Socioambientais \\
\hline Urbanismo Bioclimático & Engenharia Ambiental & $\begin{array}{c}\text { Educação para a Diversidade e } \\
\text { Meio Ambiente }\end{array}$ \\
\hline $\begin{array}{c}\text { Técnicas Construtivas } \\
\text { Não-Convencionais }\end{array}$ & Estudos Ambientais & $\begin{array}{c}\text { Ecologia e Preservação do } \\
\text { Ambiente }\end{array}$ \\
\hline
\end{tabular}

Fonte: A autora, 2020

Nestes casos, procedeu-se a pesquisa junto às ementas constantes dos Projetos Político Pedagógicos, para verificar se o termo sustentabilidade estaria presente. Para fins de cálculos, foram consideradas todas disciplinas, sejam elas obrigatórias, eletivas ou optativas, que apresentassem o termo "Sustentabilidade" em seu título ou em sua ementa (Gráfico 3 e 4).

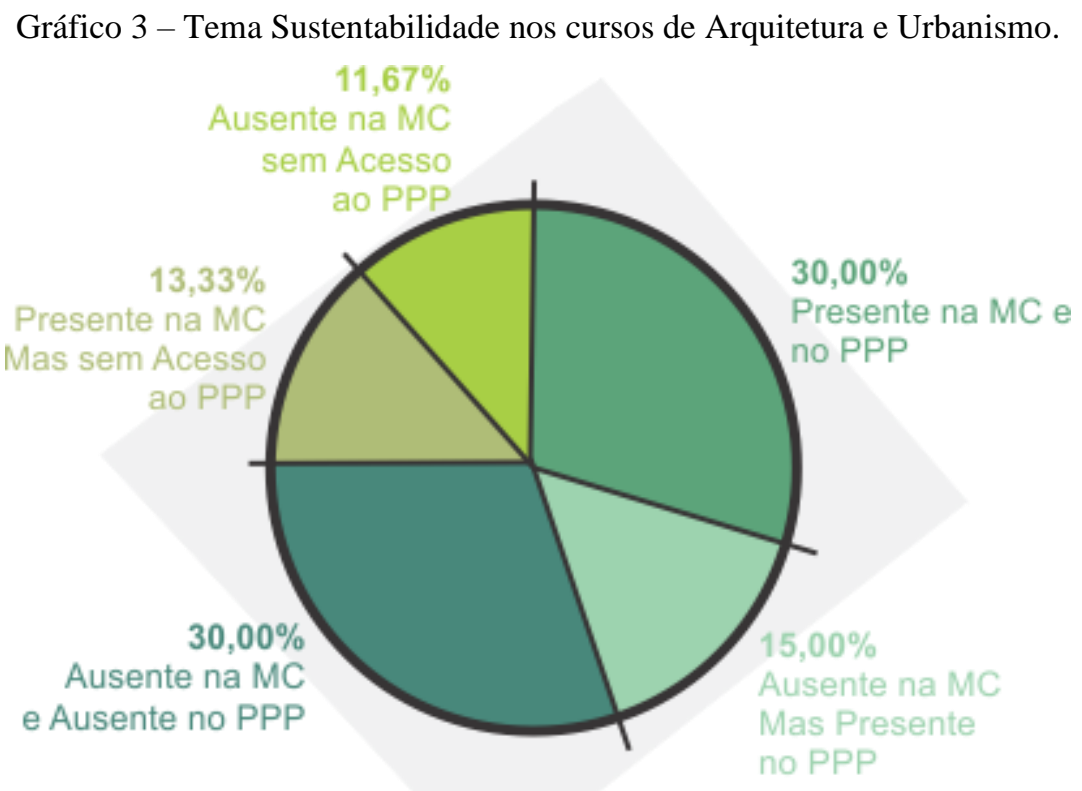

Fonte: Fonte: Os Autores, 2020. 
Gráfico 4 - Tema Sustentabilidade nos cursos de Engenharia Civil.

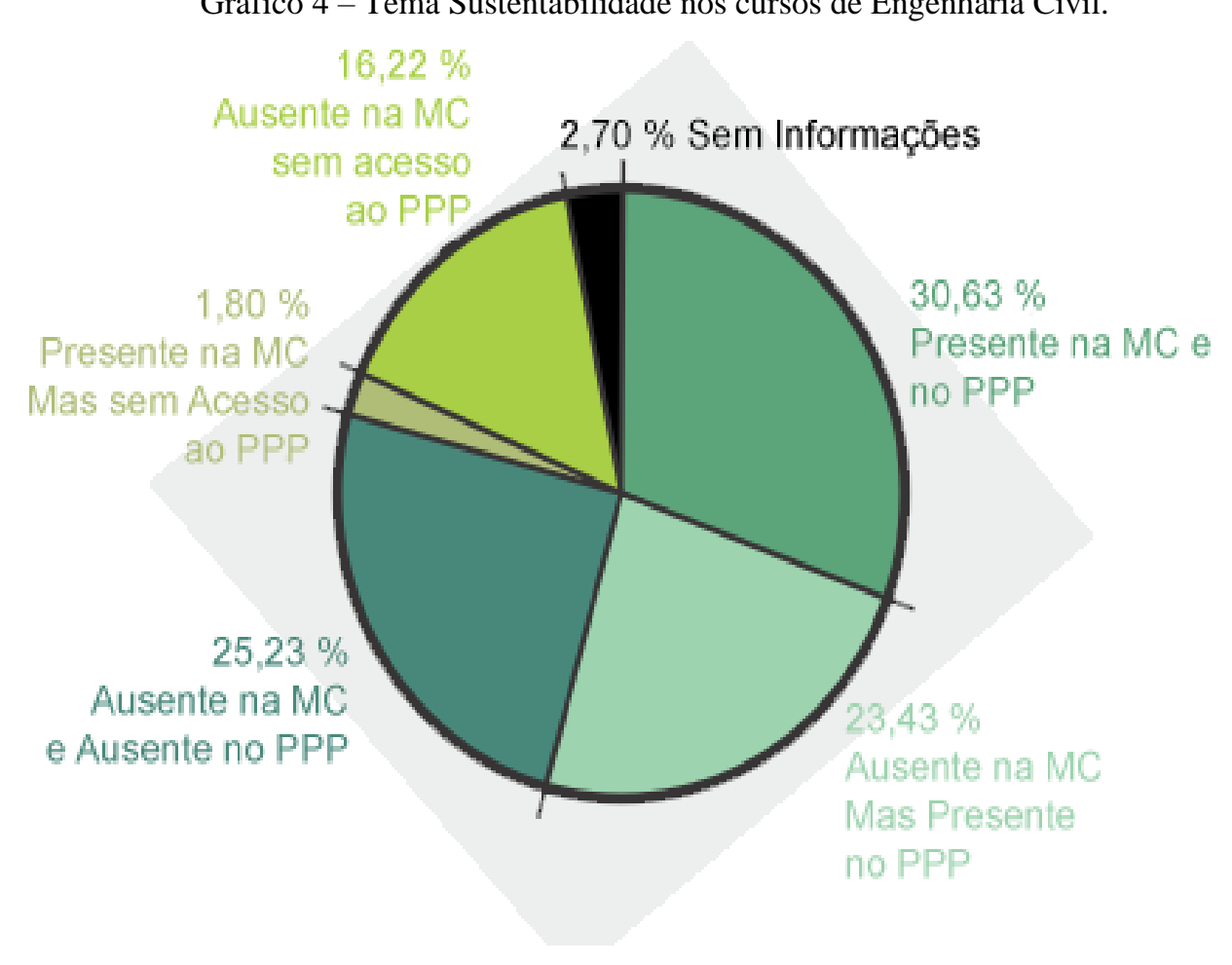

Fonte: Fonte: Os Autores, 2020.

\section{RESULTADOS E DISCUSSÃO}

Comparativamente ao estudo realizado por Souza et al. (2010), percebe-se um crescimento de $41 \%$ na oferta de cursos de arquitetura e engenharia civil em IES públicas nos últimos 10 anos. Ainda, é notável a melhora no acesso à informação disponibilizada via sites: Souza et al. (2010), tiveram acesso a apenas $49 \%$ das ementas dos cursos. Em contra partida, como fora apresentado no gráfico 2, nesta pesquisa apenas $1,75 \%$ dos cursos não dispunham de nenhum material, os demais apresentaram ao menos o currículo.

No que tange a presença do tema Sustentabilidade nos currículos, foi possível perceber leve tendência de inserção: nos estudos realizados por Souza et al. (2010), 46\% dos cursos de engenharia civil e $41 \%$ dos cursos de arquitetura analisados apresentaram o tema Sustentabilidade nos currículos; já nesta pesquisa $56 \%$ dos cursos de arquitetura e 59\% dos cursos de engenharia (Gráficos 3 e 4) trazem o tema em suas disciplinas. Entretanto, a quantidade de cursos que não mencionam o tema ainda é grande, mostrando que ainda há muito a ser trabalhado.

Foi possível também traçar um panorama da distribuição territorial do tema Sustentabilidade entre os cursos de Engenharia Civil, Arquitetura e Urbanismo das IES públicas brasileiras (Mapa 1). 
(C) COBENGE

"Os desafios para formar hoje o engenheiro do amanhã"
29 de setembro a

O2 de outubro

Bento Gonçalves/RS

Mapa 1 - Distribuição territorial do tema Sustentabilidade nos cursos de AU e ECC das IES públicas

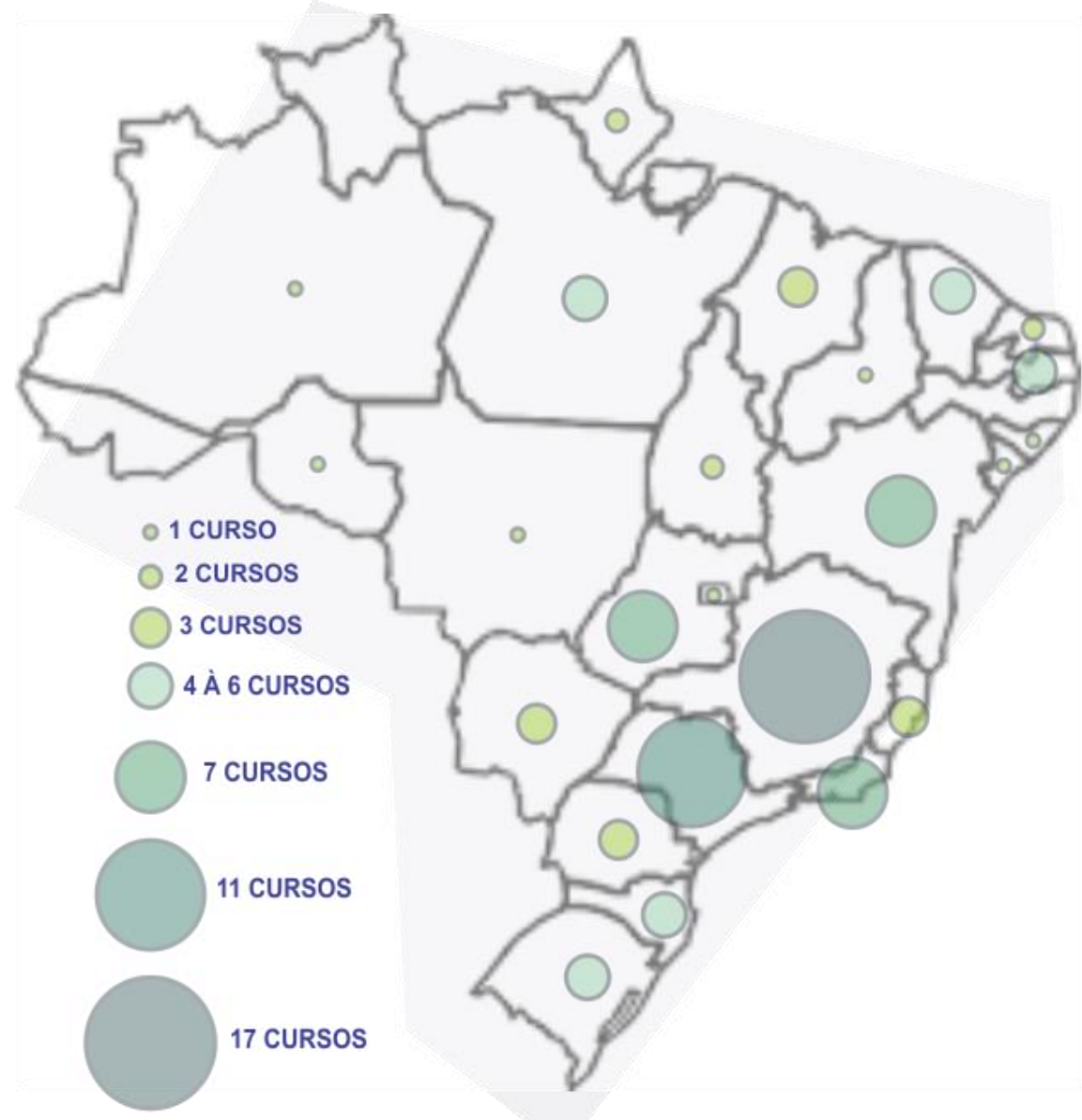

Fonte: Os autores, 2020.

Observou-se um predomínio da temática em instituições da Região Sudeste, com destaque para os estados de Minas Gerais e São Paulo, que juntos perfazem 28,87\% das instituições. Relações podem ser estabelecidas com levantamento realizado por Pergher e Freitas (2019) sobre a atuação de grupos de pesquisa voltada para o tema sustentabilidade: dos 218 grupos de pesquisa encontrados, cerca de 80 grupos (37\%) encontram-se também na região sudeste (PERGHER; FREITAS, 2019).

\section{CONSIDERAÇÕES FINAIS}

As informações levantadas por esta pesquisa apresentam um panorama da presença da temática sustentabilidade nos cursos da área da construção civil, sugerindo sobre quais regiões devem ser direcionados os esforços de reflexão e reestruturação das grades curriculares e Projetos Político Pedagógicos, de modo a promover a consolidação do tema, com vistas à formação de profissionais que dominem os conhecimentos (saber), desenvolvam habilidades (fazer) e sejam atuantes (ser) e sensíveis às demandas por parte da sociedade e do mercado de trabalho por espaços construídos mais eficientes e sustentáveis. 
(C) COBENCE

"Os desafios para formar hoje o engenheiro do amanhã"
29 de setembro a

$\mathrm{O} 2$ de outubro

Bento Gonçalves/RS

Recomendam-se mais estudos que realizem análises de abordagem qualitativa sobre os currículos apresentados, para avaliar se os conceitos de sustentabilidade se estendem às estratégias utilizadas pelos docentes, ou ainda se elas refletem uma mudança de atitude no exercício profissional dos profissionais egressos. A breve leitura dos currículos não foi suficiente para avaliar se a inserção do termo sustentabilidade acontece na prática ou se restringe ao discurso, pois em muitos casos embora o termo estivesse presente no título ou na ementa, não ficava claro nos objetivos de que forma o tema seria inserido no dia a dia da disciplina. Por vezes também as disciplinas não apresentavam bibliografia obrigatória ou complementar correlata.

Outra sugestão para trabalhos futuros, é avaliar de que forma se dá a inserção do tema sustentabilidade nos cursos, avaliando o nível de integração e colaboração entre disciplinas teóricas e práticas. Isso vai de encontro com o que é dito por Cortese (2003), onde um futuro sustentável que pressupõe uma abordagem sistêmica, que preconize a colaboração e cooperação interdisciplinar.

Uma vez que este estudo define como unidade de análise as IES públicas, por motivos já descritos no capítulo 3, sugere-se ainda que para trabalhos futuros a metodologia aplicada por este estudo seja estendida às IES privadas, que embora possuam menor quantidade de grupos de pesquisa sobre o tema se comparadas às instituições públicas, representam a maioria dos cursos de Arquitetura e Engenharia Civil brasileiras, podendo contribuir para a sondagem da presença do tema Sustentabilidade nos currículos de AEC.

\section{Agradecimentos}

Agradecimento a equipe do GPCIT, laboratório de gestão de informação da UFPR, ao PPGECC e seus professores e demais estrutura da Universidade Federal do Paraná. Também a CAPES, CNPQ e a Fundação Araucária - Governo do Estado do Paraná, pelo apoio e financiamento da pesquisa.

\section{REFERÊNCIAS}

BRASIL. Ministério da Educação (MEC). Resolução no 2, de 15 de junho de 2012:

Estabelece as Diretrizes Curriculares Nacionais para a Educação Ambiental. Rio de Janeiro, 2011. Diário Oficial do Poder Executivo, Brasília, 18 jun. 2012.

Ministério da Educação (MEC). Cadastro Nacional de Cursos e Instituições de Educação Superior - Cadastro e-MEC. Disponível em: 〈http://emec.mec.gov.br/〉. Acesso em: 27/04/2020.

\section{CORTESE, A. D. The Critical Role of Higher Education in Creating a Sustainable}

Future. Planning for Higher Education, v.31, n.3, p.15-22, March 2003. Disponível em: $<$ http://www.scup.org/asset/48483/cortese.pdf >. Acesso em: 01/05/2019.

PERGHER, R. D.; FREITAS, M. C. D. Rede de colaboração em educação aberta para engenheiro e arquiteto - disseminação de pesquisa sobre sustentabilidade. In: XLVII Congresso Brasileiro de Educação em Engenharia e II Simpósio Internacional de Educação em Engenharia da ABENGE, 2019, Fortaleza. Anais. Fortaleza, 2019.

SOUSA, C.R.; ABRAHÃO, R.C.; FREITAS, M.C. D.; TAVARES, S. F.; KRUEGER, J. A.; MENDES JUNIOR, R. Panorama dos currículos de arquitetura e engenharia civil 
sobre a inserção da temática sustentabilidade. In: José Jeferson do Rego Silva, Miguel Aloysio Sattler. (Org.). Sustentabilidade do ambiente construído. O que você tem com isso?. 1ed.Recife PE: ANTAC, 2010, v. I, p. 220-232.

XAVIER, S. P. A temática da sustentabilidade no ensino de Graduação em arquitetura e urbanismo: estudo de caso das experiências de três instituições públicas. 2011. $171 \mathrm{f}$.

Dissertação (Mestrado) - Programa de Pós-Graduação de Engenharia de Construção civil, Universidade Federal do Paraná, Curitiba, 2011.

\title{
PRESENCE OF THE SUSTAINABILITY THEME IN CURRICULUMS AND PEDAGOGICAL POLITICAL PROJECTS IN ARCHITECTURE AND CIVIL ENGINEERING COURSES
}

\begin{abstract}
Despite the passing of about 50 years of the global "ecological awakening", and in Brazil there is an expressive number of research groups on sustainability in postgraduate programs (PERGHER; FREITAS, 2019) as well as consolidated research on the subject, Sustainability is not yet a reality in Brazilian professional practice and in the built environment. This is in line with the research problem: How to make the academic production focused on environmental sustainability accessible and understandable to civil construction professionals, to equalize and democratize this knowledge produced in postgraduate courses and encourage its application in professional practice? This research is documental, exploratory, and applied, and its goal is to map the presence of the sustainability theme (within its environmental dimension) in the curriculum of the architecture and civil engineering courses in Brazilian public educational institutions (HEIs). This information will be useful for further research as it provides data on which institutions and courses lack subjects on sustainability, as well as helping to establish a network of contacts that in the next research's stage will validate the artifact to be developed - MOOC on Green Roofs, a course model that aims to share the academic production of the postgraduate program on this more sustainable construction technique with students, engineers and architects.
\end{abstract}

Keywords: Sustainability, Higher Education, Civil Construction, Architecture, Civil Engineering. 